\title{
Temporal Changes in Human Temporomandibular Joint Size and Shape ${ }^{1}$
}

\author{
ROBERT J. HINTON ${ }^{2}$ AND DAVID S. CARLSON 2.3 .4 \\ ${ }^{2}$ Department of Anthropalogy; and ${ }^{3}$ Department of Anatomy and Center for Human \\ Growth and Development, University of Michigan, Ann Arbor, Michigan 48109
}

\begin{abstract}
KEY WORDS Temporomandibular joint - Nubia - Mastication Craniofacial evolution
\end{abstract}

\begin{abstract}
Measurements approximating the size of the temporomandibular joint were taken on a series of genetically homogeneous populations from early Nubia, which span almost 10,000 years and embody a shift from a primarily hunting and gathering adaptation to a completely agricultural lifeway. A generalized trend of reduction of temporomandibular joint size was observed. In addition, a decrease in sexual dimorphism was apparent for all measures of joint size; a change primarily mitigated by reductions in male dimensions. The observed variation in size and form of the temporomandibular joint is most likely the result of the reduction in masticatory muscle robusticity and resultant changes in craniofacial form which have been documented for the transition from a hunting and gathering to an agricultural subsistence in Nubia.
\end{abstract}

The temporomandibular joint is an anatomical structure which, as the point of articulation between the cranium and the lower jaw, is of considerable importance to an under. standing of human oral function. Since the only other contact between cranium and mandible occurs indirectly through the teeth implanted in both upper and lower jaws, an interdependence between stresses on the dentition and those on the joint seems likely. Histological studies of joint structure (Sicher, '52; Rees, '54; Scheman et al., '74) coupled with studies of condyle-fossa relationships during jaw movements have confirmed that joint tissues are indeed designed to be forcebearing in those regions where the condyle is seated during tooth contact. Recent theoretical biomechanical analyses (Barbenel, '69, '72; Hekneby, '74; Hylander, '75) have also indicated that considerable stresses may impinge on the temporomandibular joint as a consequence of occlusal loading.

The probability that the temporomandibular joint may be loaded during jaw function has not been lost on researchers in clinical dentistry, who have long sought to understand the interactions between stresses on the den. tition, occlusal relations and the functional integrity of the temporomandibular joint.
Much of this research has, understandably, focused on the etiology of the multifaceted symptoms of "temporomandibular joint syndrome" (e.g., Sarnat, '64) so often encountered in clinical practice, and has thus tended to couch joint alterations due to function in a pathological framework.

A heightened appreciation of the reactions of the temporomandibular joint to functionally-induced stresses is possible from a specifically anthropological perspective: i.e., by examining situations in which occlusal stresses (and presumably stresses on the joint) are undeniably several times greater than those encountered in modern-day dental patients and for which a time depth of often thousands of years allows an assessment of joint response to a changing functional environment to be made. Bite force data on extant human populations suggest that, irrespective of body size, occlusal forces are appreciably greater in aboriginal peoples pursuing a hunt ing and gathering lifeway than in urbanized Europeans, becoming as much as three times

\footnotetext{
This rebearch was supported in part by Wenner-Gren Foundation for Anthropological Research Grant 2959 and by USPHS DE-03610 from the National Institutes of Health.

${ }^{4}$ Requests for reprints should be sent to Dr. David S. Carlson, Cen ter for Human Growth and Development, 1111 E. Catherine, Ann Arbor, Michigan 48109
} 
larger, in aboriginal Eskimos (Linderholm and Wennstrom, '70; Brekhaus et al., '37; Waugh, '37; Oppenheimer, '66; Heath, '48; Worner and Anderson, '44). That such vigorous oral function characterizes everyday existence in hunter-gatherers is attested by numerous ethnographic reports (e.g., Horne and Aston, '24; Lous, '70; Pedersen, '38, '47; Waugh, '37; Molnar, '72) and is reflected in the extensive dental attrition and chipping which such individuals commonly exhibit (Turner and Cadien, '69; Merbs, '68; Brace, '62, '67; Anderson, '65; Molnar and Ward, '77).

Unfortunately, research on temporomandibular joint morphology employing such a comparative viewpoint has been sparse. Various measures of condyle size in industrialized and aboriginal humans and in fossil hominids have been presented by Amer ('52), Morant (36), Dingwall and Young ('33), Lindblom ('60), and Oberg et al. ('71). In addition, mandibular fossa size has been assessed by Angel ('48), Lindblom ('60), Moffett ('68), Oberg et al. ('71) and Smith ('76). However, most of these studies have dealt with single samples that were temporally, spatially and culturally limited, and comparability of results has been further hindered by a general lack of commonly defined measures of joint size. Nevertheless, these scattered efforts do suggest that both components of temporomandibular joint size (i.e., mandibular fossa size and condyle size) may be considerably larger in aboriginal peoples and fossil hominids than in modern urbanized individuals. Although it seems reasonable that such disparities may be dictated in some manner by function, such an inference is tenuous indeed given the disparate and limited nature of the data sources upon which it is based. It is the purpose of this study to assess temporomandibular joint size and shape variation in a temporal series of genetically homogeneous skeletal samples that encompass appreciable changes in subsistence practices in order to evaluate the likelihood of associations between joint morphology and oral function.

\section{MATERIALS}

The majority of the skeletal remains employed in this investigation was recovered by the Scandinavian Joint Expedition to Sudanese Nubia (Nielsen, '70). They cover a time span of almost 5,000 years (ca. 3,400 B.C.-1,100 A.D.), which has traditionally been divided into five cultural horizons. Recent studies (Carl- son, '76; Carlson and Van Gerven, '77) have demonstrated that craniofacial alterations within this time span are best viewed as resulting from lessened functional demands engendered by a change in lifeway, and not from periodic migrations of different racial groups (Van Gerven et al., '73; Carlson and Van Gerven, in press). The Nubian remains thus provide an ideal sample for a study of possibly functionally-mitigated changes in the temporomandibular joint in time successive human groups who differ primarily only in mode of subsistence. Accordingly, for the purposes of this research, the cultural horizons have been combined into two groupings based on subsistence practices. The earlier sample includes the A-Group (3,400-2,400 B.C.) and CGroup (2,400-1,000 B.C.) horizons, while the latter is composed of the Meroitic (350 B.C. -350 A.D.), X-Group (350 A.D.-550 A.D.) and Christian (550-1,100 A.D.) horizons. The AC group incorporates a transition from a hunting gathering economy to a primarily agricultural one; the Meroitic-Christian (MXCh) group represents a subsistence pattern based entirely on agriculture (Adams, '70). Combining cultural horizons in this manner enables sample sizes from these two groups to be relatively large (table 1). The AC group included 52 adult crania and the MXCh around 150; for each sample, the number of males was approximately equal to the number of females thus avoiding any possibility of bias due to overrepresentation of one sex. In addition, for comparative purposes, data are included from two individuals (burials 24 and 25) from the Mesolithic sample from Wadi Halfa, Sudan, which represents a likely precursor group inhabiting the area at around 9,000 B.C. (Greene et al., '67).

\section{METHODS}

Five measurements, three expressing temporomandibular joint size and shape and two relating to the size of the masticatory mus-

TABLE 1

Composition of sample: sizes and dates

\begin{tabular}{|c|c|c|}
\hline Population & $\mathrm{N}$ & Dates \\
\hline Mesolithic & 2 & 9,000 B.C. \\
\hline A-Group (A) & 11 & $3,400-2,400$ B.C. \\
\hline C-Group (C) & 41 & $2,400-1,200$ B.C. \\
\hline Meroitic (M) & 55 & 350 B.C. 350 A.D. \\
\hline X-Group (X) & 61 & 350-550 A.D. \\
\hline Christian (Ch) & 27 & 550-1,500 A.D. \\
\hline
\end{tabular}




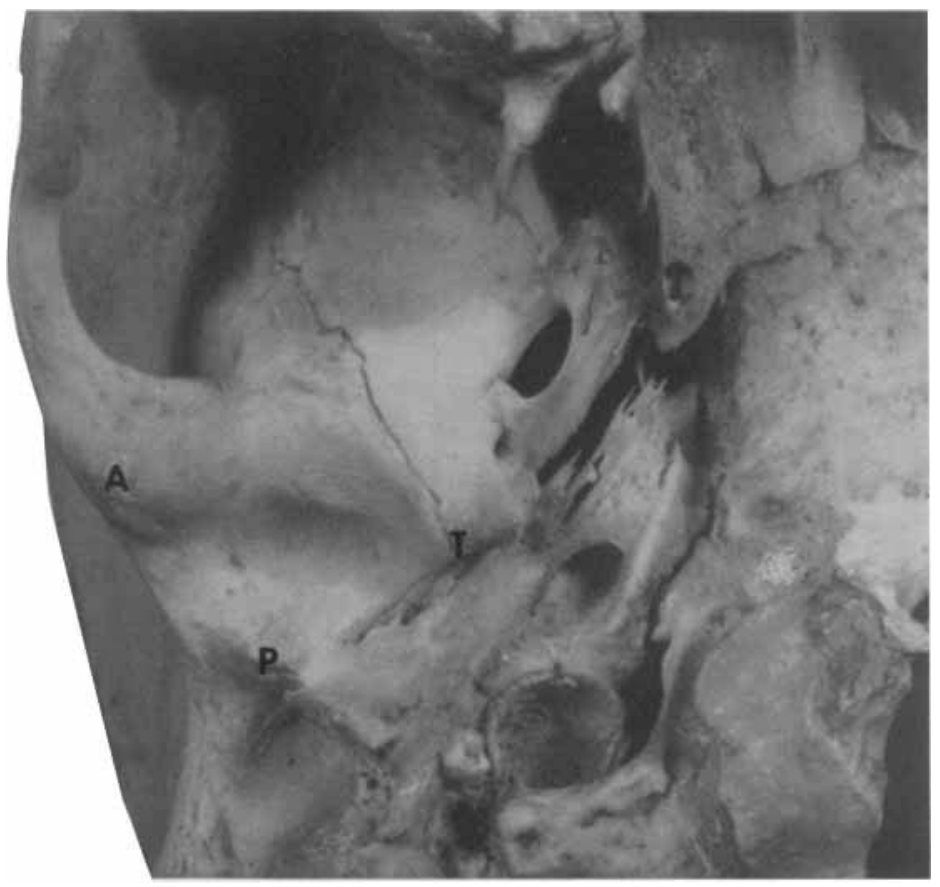

Fig. 1 Basal view of the right temporomandibular joint. P, postglenoid process; A, articular tubercle; T, temporal spine.

cles, were recorded for each skull by one of the authors (D.C.) (fig. 1):

1 postglenoid process (P) to articular tubercle (A) distance;

2 postglenoid process to temporal spine (T) (the junction of the squamosal suture and the tympanosquamosal fissure) distance;

3 temporal spine to articular tubercle distance;

4 infratemporal fossa width (the distance between the zygomatic arch and the infratem. poral crest, perpendicular to the sagittal plane);

5 width of the zygomatic arch at the midpoint of masseter attachment. All measurements were available for the vast majority of crania. The first three measurements form a triangle which approximates the size of the temporomandibular joint in the basal view. Although perhaps not of direct functional significance (but see DISCUSSION), the area of the joint triangle was calculated ${ }^{5}$ to serve as a univariate estimate of the combined effect of changes in individual joint dimensions. Simple descriptive statistics were computed for each sample as an indication of the magnitude and direction of metric changes.

\section{RESULTS}

The univariate statistical treatment re vealed that the earlier $\mathrm{AC}$ group was characterized by significantly larger temporomandibular joint size and exhibited generally greater robusticity of the masticatory musculature (as represented by variables 4 and 5 ) than the MXCh group (table 2). The disparity between the groups was even more apparent when joint area was considered, with the AC group attaining a value which exceeded that in the MXCh at a highly significant level $(\mathrm{p}<0.005)$. In addition, although measurements were possible on only two Mesolithic crania due to poor preservation of the cranial base, the values for all five parameters were truly enormous, dwarfing even those of the AC sample.

When the $\mathrm{AC}$ and $\mathrm{MXCh}$ samples were subdivided according to sex and similar statistics computed, an interesting pattern of sexual dimorphism resulted (table 3 ). Within each group all measurements were sexually dimor-

\footnotetext{
${ }^{5}$ Joint area was calculated using the formula: Area $=$ $\sqrt{\mathrm{s}(\mathrm{s} \cdot \mathrm{a})(\mathrm{s}-\mathrm{b})(\mathrm{s}-\mathrm{c})}$, where $\mathrm{s}=1 / 2(\mathrm{a}+\mathrm{b}+\mathrm{c})$ and, $\mathrm{a}, \mathrm{b}$, and $\mathrm{c}$ are sides of the joint triangle.
} 
TABLE 2

Means and standard deviations for temporomandibular joint size, infratemporal fossa width and zygomatic arch width in the Mesolithic burials and the AC and MXCh samples. Values of the $t$ statistic refer to differences between the $A C$ and $M X C h$ samples ${ }^{1}$

\begin{tabular}{|c|c|c|c|c|c|c|c|c|c|}
\hline & \multicolumn{2}{|c|}{ Mesolithic } & \multicolumn{3}{|c|}{$\mathrm{AC}$} & \multicolumn{3}{|c|}{$\mathrm{MXCh}$} & \multirow[b]{2}{*}{$\mathbf{T}$} \\
\hline & $\mathrm{B} 25$ & B24 & $\mathrm{N}$ & Mean & S.D. & $\mathrm{N}$ & Mean & S.D & \\
\hline \multicolumn{10}{|l|}{ Postglenoid process to articular } \\
\hline $\begin{array}{l}\text { Postglenoid process to } \\
\text { temporal spine }\end{array}$ & 19.4 & 16.4 & 52 & 16.64 & 1.85 & 143 & 16.16 & 1.49 & 1.84 \\
\hline \multicolumn{10}{|l|}{ Temporal spine to articular } \\
\hline spine & 25.0 & 27.0 & 52 & 23.31 & 2.76 & 143 & 22.26 & 2.14 & $2.81^{3}$ \\
\hline Infratemporal fossa width & 27.0 & 31.5 & 48 & 22.82 & 2.74 & 138 & 22.81 & 2.46 & 0.003 \\
\hline Zygomatic arch width & 5.0 & 5.1 & 51 & 3.82 & 1.17 & 141 & 3.49 & 9.7 & 1.93 \\
\hline Mandibular fossa area & 190.3 & 166.9 & 52 & 135.79 & 23.07 & 143 & 125.23 & 19.00 & $3.23^{3}$ \\
\hline
\end{tabular}

${ }^{1}$ All measurements are in millimeters, except for mandibular fossa area, which is given in square millimeters.
${ }^{2} p<0.05$.

$\mathrm{p}<0.01$.

TABLE 3

Sexual dimorphism within the $A C$ and $M X C h$ groups

\begin{tabular}{|c|c|c|c|c|c|c|c|c|}
\hline & \multicolumn{3}{|c|}{ AC malea } & \multicolumn{3}{|c|}{ AC females } & \multirow{2}{*}{$\begin{array}{l}\text { Percentage } \\
\text { sexual } \\
\text { dimorphism }^{2}\end{array}$} & \multirow[b]{2}{*}{$\mathbf{t}$} \\
\hline & $\mathrm{N}$ & Mean & S.D. & $\mathrm{N}$ & Mean & S.D. & & \\
\hline \multicolumn{9}{|l|}{ Postglenoid process to } \\
\hline \multicolumn{9}{|l|}{ Postglenoid process to } \\
\hline temporal spine & 28 & 17.31 & 1.72 & 24 & 15.85 & 1.72 & 8 & $3.05^{4}$ \\
\hline \multicolumn{9}{|l|}{ Temporal spine to articular } \\
\hline tubercle & 28 & 24.56 & 2.04 & 24 & 21.85 & 2.79 & 11 & $4.03^{4}$ \\
\hline Infratemporal fossa width & 27 & 23.72 & 2.73 & 21 & 21.65 & 2.32 & 9 & $2.78^{4}$ \\
\hline Zygomatic arch width & 28 & 4.13 & 1.39 & 23 & 3.44 & 0.69 & 17 & $2.17^{3}$ \\
\hline \multirow[t]{3}{*}{ Mandibular fossa area } & 28 & 145.96 & 21.87 & 24 & 123.90 & 18.58 & 15 & $3.88^{4}$ \\
\hline & \multicolumn{3}{|c|}{ MXCh males } & \multicolumn{3}{|c|}{ MXCh females } & \multirow{2}{*}{$\begin{array}{l}\text { Percentage } \\
\text { sexual } \\
\text { dimorphism }\end{array}$} & \multirow[b]{2}{*}{$\mathbf{t}$} \\
\hline & $\mathrm{N}$ & Mean & S.D. & $\mathbf{N}$ & Mean & S.D. & & \\
\hline \multicolumn{9}{|l|}{ Postglenoid process } \\
\hline \multicolumn{9}{|l|}{ Postglenoid process to } \\
\hline temporal spine & 71 & 16.60 & 1.43 & 72 & 15.73 & 1.44 & 5 & $3.59^{4}$ \\
\hline \multicolumn{9}{|l|}{ Temporal spine to } \\
\hline articular tubercle & 71 & 22.79 & 1.85 & 72 & 21.73 & 2.29 & 5 & $3.05^{4}$ \\
\hline Infratemporal fossa width & 68 & 23.50 & 2.34 & 70 & 22.14 & 2.40 & 6 & $3.37^{4}$ \\
\hline Zygomatic arch width & 70 & 3.68 & 0.94 & 71 & 3.31 & 0.98 & 10 & $2.29^{3}$ \\
\hline Mandibular fossa area & 71 & 130.67 & 16.57 & 72 & 120.26 & 20.03 & 8 & $3.25^{4}$ \\
\hline
\end{tabular}

All measurements are in millimeters, except for mandibular fossa area, which is given in square millimeters.

${ }^{2}$ Computed by the formula: $\left(\left(\delta \mathrm{x}-\sigma_{\mathrm{x}}\right) / \delta \mathbf{x}\right) \times 100$

${ }^{3} \mathrm{p}<0.05$.

$4 \mathrm{p}<0.01$.

phic at $\mathrm{p}<0.05$ or greater, with the exception of postglenoid process to articular tubercle distance. This suggests that males exhibit significantly greater robusticity with respect to the masticatory musculature and appreciably larger temporomandibular joints than do females. Exactly the same results were obtained for the MXCh group. While this was not particularly surprising, in light of male- female differences in other cranial dimensions, differential changes in males and females over time (i.e., from $\mathrm{AC}$ to $\mathrm{MXCh}$ ) elabo rate on this trend (fig. 2). Only measures of temporomandibular joint size showed any sig. nificant degree of dimorphism between groups, and the differences were confined to males only. In nearly every case, the female values changed little if at all, while male 


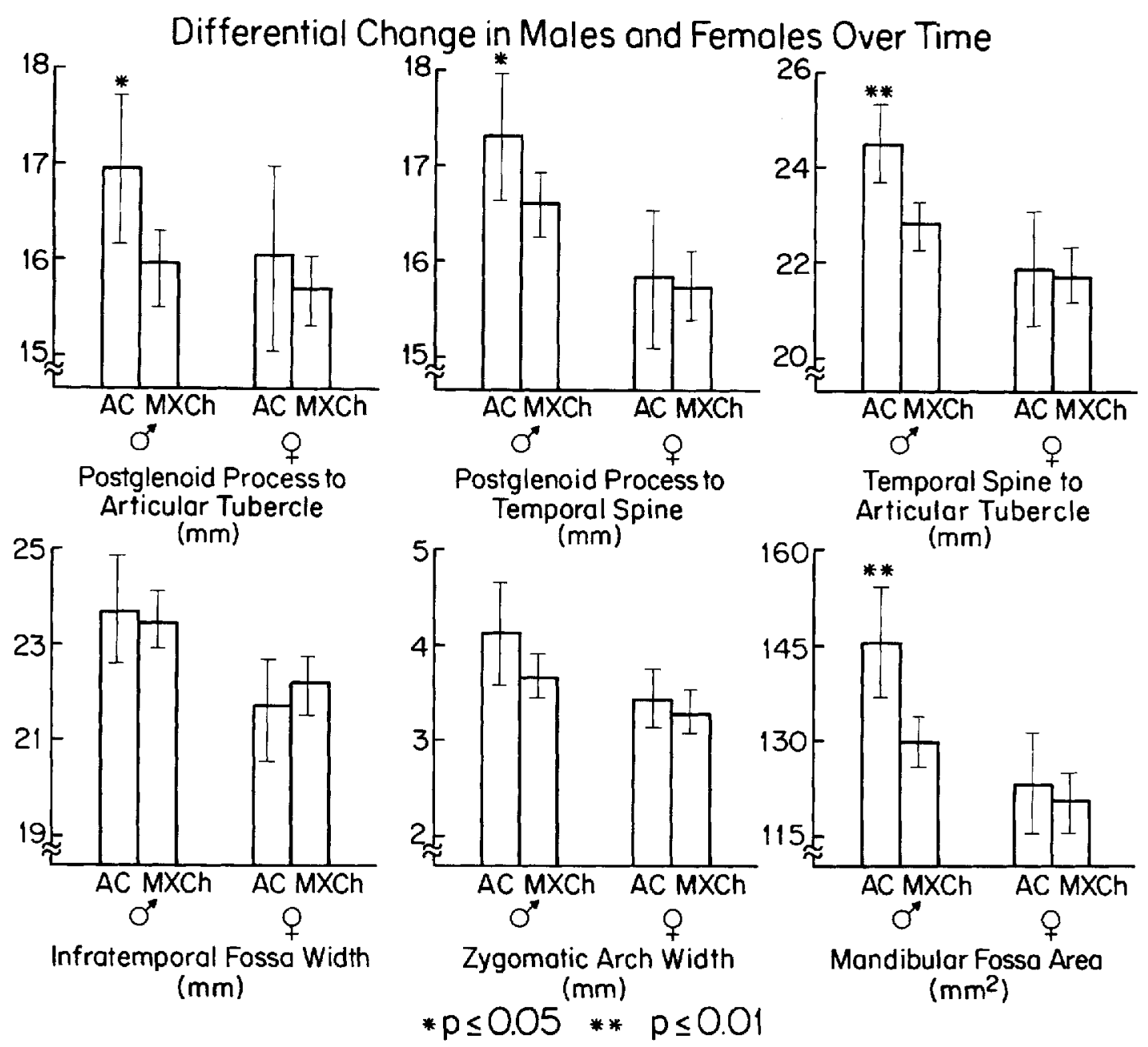

Fig. 2 Differential change between males and females over time. AC males are compared with $\mathrm{MXCh}$ males, while AC females are compared with MXCh females for each variable.

values were different for each parameter of temporomandibular joint size at $p<0.05$ or greater. Indeed, temporomandibular joint area decreased by only 3 percent in females (non-significant) but by $12 \%$ percent in males (significant at $p<0.001$ ). Thus, percentage sexual dimorphism decreased in every case over time from the $\mathrm{AC}$ to the MXCh groups, and reductions in male temporomandibular joint size and masticatory muscle robusticity appeared to underlie such a trend (table 2).

\section{DISCUSSION}

The results presented above support scattered inferences in the literature that man- dibular fossa size is indeed appreciably larger in those pursuing a hunting and gathering lifeway than in those practicing an agricultural mode of subsistence. While the assertion must remain tentative, indications are persuasive that such a disparity may reasonably be judged a consequence of differing oral function in the two groups. This assertion is further supported by the very large dimensions of the temporomandibular joint in the Nubian Mesolithic, a sample which clearly exhibits both cranial and dental indications of severe masticatory stress (Greene et al., '67). Such stress is also reflected by the evidence of temporomandibular trauma and associated 
pathologies in this group (Greene and Armelagos, '72) and in a North African Mesolithic sample (Ferembach, '62).

The changes in temporomandibular joint size described above might be plausibly attributed to the effects of body or skull size, given our incomplete understanding of such relationships. Demirjian ('67) has presented evidence that fossa length and width are positively correlated with overall cranial dimensions. However, the transition from the $\mathrm{AC}$ to the $\mathrm{MXCh}$ groups involves a distinct increase in cranial height relative to its length, resulting in, if anything, a larger cranium (Carlson, '76; Carlson and Van Gerven, '77). Moreover, stature remains constant or even increases slightly in the MXCh period (Masali, '72). Accordingly, if temporomandibular joint size were strongly mediated by cranial or body size, it would be expected to become larger in the MXCh sample-exactly the opposite of what is observed.

A much more pertinent change is the marked decrease in the size of the muscles of mastication coupled with their relatively more posterior sites of origin in the MXCh group, implying a reduction in functional demands placed on the masticatory complex (Carlson and Van Gerven, '77). As noted previously, biomechanical analyses of human mastication have made it clear that the temporomandibular joint, or actually the articular eminence, may be subjected to considerable stresses resulting from strenuous oral function. Recent studies have indicated that the lower jaw functions as a simple lever during incisal biting, with the temporomandibular joints acting as fulcrums bilaterally $(\mathrm{Hy}$ lander, '75). The situation during unilateral molar chewing is much more complex, with the loaded axis extending from the bite point on one side to the condyle on the opposite. In this configuration, the contralateral condyle (on the side opposite the bite point) receives the brunt of the forces impinging on the jaw joints. However, these forces may be minimized by the interplay of masticatory muscles on the chewing and non-chewing sides (Gibbs et al., '71; Hylander, '75). Hence, it is likely that joint reaction forces may be noticeably greater under conditions of strenuous incisal biting than in unilateral molar chewing (Barbenel, '69, '72; Hekneby, '74). The numerous ethnographic accounts of vigorous anterior tooth function in hunting and gathering peo- ples coupled with the documented decrease in size and posterior positioning of the masticatory musculature in the MXCh groups make it likely that changes in temporomandibular joint size represent a response to altered intensity and perhaps patterning of oral function: i.e., that the mandibular fossa exhibits, in some fashion, a larger overall size in the earlier groups as a means of equilibrating the effects of increased joint reaction forces resulting from vigorous oral function.

Since the loaded condyle is not seated within the fossa during the functional phases of mastication but rather is positioned at some point on the articular tubercle, it seems probable that mandibular fossa size is not directly affected by occlusal loading. Rather, given indications of close developmental synchrony between condyle and fossa in humans (Oberg et al., '71; Kazanjian, '39) and in monkeys (Phillips, '76), condyle size may be the structure exhibiting direct adaptational responses to joint reaction forces, with fossa size a secondary adjustment to accommodate the larger condyle. Although condyle size data are not available for the Nubian samples under consideration here, there are indications that condyle size varies widely in human populations (Weidenreich, '36), with the largest to be found in hunting and gathering peoples (Hinton, unpublished data; Wallace, '27) and in fossil hominids (Smith, '76; Wolpoff, '75; White, '77). The adaptive role of the trabecular structure of the condylar head and neck in withstanding compressive forces has been emphasized by Hylander ('75). Wolpoff ('75) has even suggested that condylar breadth may be viewed as a direct indication of the magnitude of forces impinging on the condyle during oral function. In addition, there is a limited body of experimental evidence implicating induced changes in dietary consistency as a causative agent for increases in masticatory muscle attachment areas, mandibular corpus thickness, density of condylar bone and condyle size in rats (Watt and Williams, '51; Barber et al., '63; Moore, '65). Also, in a monkey with unilateral paralysis of the masticatory muscles, Rogers ('55) noted a decrease in ipsilateral condyle size coupled with a hypertrophy of the contralateral condyle and musculature.

At the histological level, the growth processes of the condyle have been the subject of intense scrutiny. It is clear that the condylar cartilage is not an independent growth center 
as once thought, but is rather a site of compensatory growth which adapts to alterations in jaw function and occlusal relations (Durkin et al., '73; Petrovic et al., '75; Koski, '77; McNamara, '72). In this regard, Simon ('77) has implicated loss of incisal biting capability as the causative agent for reduced condylar cartilage proliferation in rats whose incisors were trimmed and/or removed. Moreover, Carlson et al. (78) have linked changes in the location and thickness of condylar cartilage layers in growing rhesus monkeys to alterations in magnitude and direction of joint reaction forces resulting from growth-engendered position changes in the masticatory musculature. These studies and others indicate that occlusal function may be the primary determinant of both the location and extent of the cartilage proliferation that in the final analysis constitutes growth of the condyle. An extrapolation of these experimental findings to those presented previously makes it probable that increased condyle size, and indirectly mandibular fossa size, represents a compensatory response to strenuous oral function during growth.

However, while mandibular fossa size as a whole may be regarded in an adaptive context, it does not necessarily follow that this will hold true for each of its constituent measurements. Most notably, postglenoid process-articular tubercle (P-A) distance is the only temporomandibular joint dimension not to exhibit a statistically significant difference between males and females (table 3 ). This is of interest in light of striking dimorphism in joint length demonstrated by Phillips ('76) in monkeys. Phillips, who studied temporomandibular joint morphometrics in relation to craniofacial parameters in an age-graded series of macaque skulls, noted that while measures of joint width seemed to be influenced by robusticity and size factors in the craniofacial skeleton, those of joint length (such as P-A distance in this study) appeared to be quite independent of general size. While supporting the concept of joint size as responsive to biomechanical factors involving the dentition, Phillips also suggests that such a relationship may be tempered to some degree by developmental constraints engendered by competing requirements of the many structures in the cranial base. Given the smaller anteroposterior component of facial growth in humans as compared with monkeys and apes (Enlow,
'66) it is possible that such spatial limitations may exert a more powerful influence on joint development in humans, thus accounting for the lack of sexual dimorphism observed in this study. Such contrasting evidence should provide impetus for further research into this matter. In any case, the significant intergroup decrease in joint length (P-A) (table 2) makes it probable that, in a temporal perspective, variation in this parameter, like other aspects of temporomandibular joint size, may reflect the influence of oro-functional factors (Oberg et al., ' 71 for similar indications).

The finding of appreciable sexual dimorphism for mandibular fossa size can perhaps not be attributed solely to differing functional demands since body and cranial size differences between males and females often exist in addition to differences in masticatory muscle robusticity. While Lindblom ('60) has previously noted the possible existence of male-female differences in fossa size, current understanding of correlations of human temporomandibular joint size parameters with measures of skull size does not allow partitioning of this variation into size and functional components. However, it is perhaps significant that as percentage sexual dimorphism in masticatory muscle rugosity (but not body or cranial size) declines from the AC to the $\mathrm{MXCh}$ groups (table 2), all three measures of temporomandibular joint size reduce also, implying the existence of some functionallymediated component. Moreover, the achievement of this lessening sexual dimorphism primarily by means of reduction in male dimensions requires notice in light of its striking similarity to the model presented for Upper Paleolithic and Mesolithic tooth size reduction by Frayer ('76, '77), and that for the decrease in cranial rugosity in the transition from Neanderthal to Late Upper Paleolithic by Wolpoff ('75); i.e., reduction of dimorphism chiefly by gracilization of the males.

\section{CONCLUSIONS}

Changes in temporomandibular joint dimensions have been demonstrated for a timesuccessive series of genetically contiguous skeletal samples which span up to 10,000 years and represent a transition from a primarily hunting and gathering economy to one of sedentary agriculture. Specifically, it has been shown that:

1 dimensions of joint length and width, 
together with mandibular fossa area, exhibited highly significant decreases over the time period outlined; the most striking differences between the groups occurred in measures of joint width;

2 appreciable sexual dimorphism for measures of fossa width (males larger), but not length, was present within both groups;

3 percentage sexual dimorphism for all parameters of joint size reduced from the earlier to later grouping, a trend which resulted primarily from reduction in male dimensions;

4 changes in mandibular fossa dimen. sions are paralleled by similar decreases in size, rugosity and more posterior positioning of the masticatory muscles in the later agricultural populations;

5 since no marked decrease in stature or cranial size is evident over the time period in question (actually, somewhat the opposite trend occurs), larger fossa size in the earlier group may represent a means of equilibrating increased joint reaction forces resulting from vigorous oral function, perhaps indirectly as an accommodation to increased condyle size.

\section{LITERATURE CITED}

Adams, W. Y. 1970 A re-appraisal of Nubian culture history. Orientalia, 39: 269-277.

Amer, A. 1952 Approach to surgical diagnosis of the temporomandibular articulation through basic studies of the normal. J. Am. Dent. Ass., 45: 668-688.

Anderson, J. E. 1965 Human skeletons of Tehuacan. Science, 148: 496-497.

Angel, J. L. 1948 Factors in temporomandibular joint form. Am. J. Anat., 83: 223-246.

Barbenel, J. C. 1969 Analysis of forces at the temporomandibular joint during function. Dent. Pract. Dent. Rec., 19: 305-310.

1972 The biomechanics of the temporomandibular joint: a theoretical study. J. Biomech., 5: 251-256.

Barber, C. G., L. J. Green and G. J. Cox 1963 Effects of the physical consistency of diet on the condylar growth of the rat mandible. J. Dent. Res., 42: 848-851.

Brace, C. L. 1962 Cultural factors in the evolution of the human dentition. In: Culture and the Evolution of Man. M. F. A. Montagu, ed., Oxford Univ. Press; New York, pp. 343-354.

1967 Environment, tooth form and size in the Pleistocene. J. Dent. Res., 46: 809-816.

Brekhaus, P., W. D. Armstrong and W. J. Simon 1937 Strength of bite and condition of teeth in men and supermen. J. Dent. Res., 16: 309.

Carlson, D. S. 1976 Temporal variation in prehistoric Nubian crania. Am. J. Phys. Anthrop., 45: 467-484.

Carlson, D. S., J. A. McNamara, Jr. and D. H. Jaul 1978 Histological analysis of the growth of the mandibular condyle in the rhesus monkey (Macaca mulatta). Am. J. Anat., 151: 103-118.

Carlson, D. S., and D. P. Van Gerven 1977 Masticatory function and post-Pleistocene evolution in Nubia. Am. J. Phys. Anthrop., 46: 495-506.
1979 Diffusion, biological determinism and biocultural adaptation in the Nubian corridor. Amer. Anthrop., in press.

Demirjian, A. 1967 A study of the morphology of the glenoid fossa. Nat'l. Mus. Canada Bull. 206, pt. V: 1-25.

Dingwall, D., and M. Young 1933 The skulls from excavations at Dunstable, Bedfordshire. Biometrika, 25: $147-157$

Durkin, J., J. Heeley and J. T. Irving 1973 The cartilage of the mandibular condyle. Oral Sci. Rev., 2: 29-99.

Enlow, D. H. 1966 A comparative study of facial growth in Homo and Macaca. Am. J. Phys. Anthrop., 24: 293-308.

Ferembach, D. 1962 La Necropole Eppaleolithique de Taforalt: Etude des Squellettes Humains. Centre National de la Recherche Scientifique, Mission Universitate et Culturelle Francaise au Maroc, Rabat.

Frayer, D. W. 1976 Evolutionary Dental Changes in Upper Paleolithic and Mesolithic Human Populations. Ph.D. dissertation, University of Michigan, Ann Arbor. 1977 Dental sexual dimorphism in the European Upper Paleolithic and Mesolithic. J. Dent. Res., 56: 871

Gibbs, C. H., T. Messerman, J. B. Reswick and H. J. Derda 1971 Functional movements of the mandible. $J$. Prothet. Dent., 26: 604-620.

Greene, D. L., and G. Armelagos 1972 The Wadi Halfa Mesolithic population. Research Report No. 11, Department of Anthropology, University of Massachusetts, Am. herst.

Greene, D. L., G. H. Ewing and G. J. Armelagos 1967 Dentition of a Mesolithic population from Wadi Halfa, Suda Am. J. Phys. Anthrop., 27: 41-56.

Heath, J. 1948 Facial form and biting pressure. Aust. J Dent., 52: 253-255.

Hekneby, M. 1974 The load of the temporomandibular joint: physical calculations and analyses. J. Prothet. Dent., 31: 303-312.

Horne, G., and G. Aston 1924 Savage Life in Central Australia. MacMillan, London.

Hylander, W. 1975 The human mandible: lever or link? Am. J. Phys. Anthrop., 43: 227-242.

Kazanjian, V. H. 1939 Congenital absence of the ramus of the mandible. J. Bone Joint. Surg., 21: 761-772.

Koski, K. 1977 The role of the craniofacial cartilages in the postnatal growth of the craniofacial skeleton. In: Orofacial Growth and Development. A. A. Dahlberg and T. Graber, eds., Mouton, The Hague, pp. 9.34.

Lindblom, G. 1960 On the Anatomy and Function of the Temporomandibular Joint. A. B. Fahlerantz, Boktryckeri, Stockholm.

Linderholm, H, and A. Wennstrom 1970 Isometric bite force and its relation to general muscle force and body build. Acta. Odontol. Scand., 28: 679-689.

Lous, I. 1970 The masticatory system as a tool. Dent. Abstr., 15: $457-458$.

Masali, M. 1972 Body size and proportions as revealed by bone measurements and their meaning in environmental adaptation. J. Hum. Evol., 1: 187-197.

McNamara, J. A., Jr. 1972 Neuromuscular and Skeletal Adaptations to Altered Orofacial Function. Center for Human Growth and Development, Ann Arbor.

Merbs, C. F, 1968 Anterior tooth loss in arctic populations. Southwest. J. Anthrop., 24: 20-32.

Moffett, B. C. 1968 The temporomandibular joint. In: Complete Denture Prosthodontics. J. J. Sharry, ed., McGraw Hill, New York, pp. 56-104.

Molnar, S. 1972 Tooth wear and culture: a survey of tooth functions among some prehistoric populations. Curr. Anthrop., 13: 511-526.

Molnar, S., and S. C. Ward 1977 On the hominid mastica- 
tory complex: biomechanical and evolutionary perspectives. J. Hum. Evol, 6: 557-568.

Moore, W. J. 1965 Masticatory function and skull growth. J. Zool., 146: 123-131.

Morant, G. M. 1936 A biometric study of the human mandible. Biometrika, 28: 84-122.

Nielsen, $O$. Vagn 1970 The Nubian Skeleton Through 4,000 Years. Thesis, Andelsbogtrykkeriet, Odense, Denmark.

Oberg, T., G. E. Carlson and C.-M. Fajers 1971 The temporomandibular joint. A morphologic study on a human autopsy material. Acta Odontol. Scand., 29: 349.384.

Oppenheimer, A. M. 1966 On tool use and crowded teeth: reply. Curr. Anthrop., 7: 357-359.

Pedersen, P. O. 1938 Investigation into the dental conditions of about 3,000 ancient and modern Greenlanders. Dent. Res., 58: 191-198.

1947 Dental investigations of Greenland Eskimos. Proc. Roy. Soc. Med., 40: 726-732.

Petrovic, A. G., J. J. Stutzmann and C. L. Oudet 1975 Control processes in the postnatal growth of the condylar car. tilage of the mandible. In: Determinants of Mandibular Form and Growth, J. A. McNamara, Jr, ed., Center for Human Growth and Development, Ann Arbor, pp. 101-154.

Phillips, C. L. 1976 Growth and Form of the Temporomandibular Joint of Macaca mulatta in Relation to Craniofacial Proportions. Ph.D. thesis. University of Wisconsin-Madison.

Rees, L. A. 1954 The structure and function of the mandibular joint. Brit. Dent. J., 96: 125-133.

Rogers, W. M. 1955 Experimental changes similar to asymmetry observed in bulbar polio in the skull and mandible of monkey. Anat. Rec., 121: 357-358.

Sarnat, B. G., ed. 1964 The Temporomandibular Joint. C. C Thomas, Springfield.

Scheman, P., M. Milstoc and M. Rubin 1974 T. M. J. tra- beculation as an expression of joint function. N. Y. State Dent. J., 40: 595-600.

Sicher, H. 1952 Functional anatomy of the temporoman dibular articulation. Dent. J. Aust., 24: 1-14.

Simon, M. R. 1977 The role of compressive forces in the normal maturation of the condylar cartilage in the rat. Acta Anat., 98: 351-360.

Smith, F. H. 1976 The Neanderthal Remains from Kra pina: a Descriptive and Comparative Study. Report of In vestigations Number 15, Dept. of. Anthropology, Univ. of Tennessee, Knoxville.

Turner, C. G. II, and J. D. Cadien 1969 Dental chipping in Aleuts, Eskimos, and Indians. Am. J. Phys. Anthrop., 31. 303-310.

Van Gerven, D. P., D. S. Carlson and G. J. Armelagos 1973 Racial history and bio-cultural adaptation of Nubian archeological populations. J. Afr. Hist., 14: 555-564.

Wallace, J. S. 1927 Variation in the Form of the Jaws. Bailliere, Tindall and Cox, London.

Watt, P.G., and H. M. Williams 1951 The effects of the physical consistency of food on the growth and development of the mandible and maxilla of the rat. Am. J. Orthodont. 37: 895-928.

Waugh, L. M. 1937 Dental observations among Eskimos. J. Dent. Res., 16: 355-356.

Weidenreich, F. 1936 The Mandibles of Sinanthropus pekinesis, Palaeont. Sin., Ser. D, No. 4, 7: 1-162.

White, T. D. 1977 The Anterior Mandibular Corpus of Early African Hominidae: Functional Significance of Shape and Size. Ph.D. dissertation, Univ, of Michigan, Ann Arbor.

Wolpoff, M. H. 1975 Some aspects of human mandibular evolution. In: Determinants of Mandibular Form and Growth. J. A. MeNamara, Jr., ed., Center for Human Growth and Development, Ann Arbor, pp. 1-64.

Worner, H. K., and M. N. Anderson 1944 Biting force mea surements on children. Aust. J. Dent., 47: 1-12. 